\title{
Article
}

\section{'Through the lens of ethnography': Perceptions, challenges, and experiences of an early career practitioner-researcher in professional football}

Champ, Francesca Mary, Ronkainen, Noora, Nesti, Mark S., Tod, David and Littlewood, Martin

Available at http://clok.uclan.ac.uk/29086/

Champ, Francesca Mary ORCID: 0000-0002-9319-8292, Ronkainen, Noora, Nesti, Mark S., Tod, David and Littlewood, Martin (2020) 'Through the lens of ethnography': Perceptions, challenges, and experiences of an early career practitioner-researcher in professional football. Qualitative Research in Sport, Exercise and Health, 12 (4). pp. 513-529. ISSN 2159-676X

It is advisable to refer to the publisher's version if you intend to cite from the work. http://dx.doi.org/10.1080/2159676X.2019.1638444

For more information about UCLan's research in this area go to http://www.uclan.ac.uk/researchgroups/ and search for <name of research Group>.

For information about Research generally at UCLan please go to http://www.uclan.ac.uk/research/

All outputs in CLoK are protected by Intellectual Property Rights law, including Copyright law. Copyright, IPR and Moral Rights for the works on this site are retained by the individual authors and/or other copyright owners. Terms and conditions for use of this material are defined in the policies page. 
'Through the Lens of Ethnography': Perceptions, Challenges, and Experiences of an Early Career Practitioner-Researcher in Professional Football

3

4 Francesca M Champ ${ }^{a *}$, Noora. J. Ronkainen ${ }^{b}$, Mark. S. Nesti ${ }^{b}$, David. A. Tod ${ }^{b}$, Martin.

$5 \quad$ A. Littlewood ${ }^{b}$

6 aDepartment of Sport, Exercise, and Nutritional Sciences, University of Central

7 Lancashire, Preston, United Kingdom; 'bport and Exercise Sciences, Liverpool John

8 Moores University, Liverpool, United Kingdom

9 *fmchamp@uclan.ac.uk, @fchamp1

10 Word Count: 8796

11

12

13

14

15

16

17

18

19

20

21

22

23

24

25 
27 The present study critically explores the use of practitioner-researcher ethnography in professional football, and illustrates some of the challenges that the first author experienced as a result of the dual-role occupation. The first author occupied the position of insider sport psychology practitioner-researcher within one professional football club over a 3-year duration. Traditional ethnographic research methods were employed, including; observations, field notes, and reflections. Following thematic analysis, research on the potential for conflict and tension in ethnography, and ethical guidelines from caring professions (e.g. sport psychology, health, and nursing) were used to make sense of the data. A series of reflective extracts highlight moral, ethical, and personal challenges of occupying a dual role, including threats to identity, acceptance of academics in elite sport, and confidentiality. For those individuals whose livelihood is dependent on their successes as a practitioner-researcher an understanding of how to overcome methodological challenges will be beneficial in improving their organisational status.

40 From the results of this study, we suggest that a range of support mechanisms (e.g. 41 ethnographers club, regional support hubs, supervisor/researcher training and education), and the development of a clear sense of self are essential for the ethnographic practitionerresearcher. 
Qualitative researchers in sport, exercise, and health have increasingly started to look for ways to expand and diversify the methodological landscape of these fields (e.g. Champ et al., 2018; Devaney et al., 2018; Spracklen et al., 2010). Although quantitative, mixed methods, and structured qualitative methods (e.g. questionnaires, semi-structured interviews, focus groups) have been beneficial in developing our understanding of the relationship between psychological characteristics/variables/interventions on sports performance (see Scott-Hamilton et al., 2016), there are several limitations to these methods. For example, questionnaires and structured interviews provide us with a limited contextual understanding of the lived experiences of athletes and their support staff in their everyday life. This is due to the inability of the researcher to embed themselves within the subculture across time (Champ et al., 2018; Gough, 2016). Furthermore, these methods often rely on participant's retrospective recall of an event or situation, and responses are constrained by the questions being asked of them (Ragin, 2014).

Ethnography has been offered as one promising approach for studying experiences in sport, exercise, and health contexts (or more specifically, sport psychology) because it enables researchers to immerse themselves within a setting to develop a more in-depth understanding of specific subcultures and their social interactions, language practices and behaviours (Maitland, 2012). Secondly, ethnography offers the opportunity for researchers to create new forms of knowledge and understanding (Krane \& Baird, 2005). However, despite its promises, this method also brings several challenges especially for those who want to study organisations (Lillis, 2008; Arber, 2006; Coy, 2006). For example, Arber (2006) described feelings of betrayal and frustration when making difficult decisions that might influence a stakeholder's position within the organisation. Adams, Ellis, and Jones (2017) built upon this work and 
identified the challenges of negotiating working practices, and developing a shared understanding of language. Sociological work conducted by Cushion (2001) and Parker (1995) highlighted gaining access, developing relationships, and establishing the participants' trust as barriers to this type of research in professional football. Therefore, this paper will provide a more focused exploration of the use and application of practitioner-researcher ethnography specific to applied sport psychology. Ethnography has its roots in the social anthropologies of the early $20^{\text {th }}$ century. More recently, ethnography has been used in education (Corrigan, 1979; Fleming, 1995; Lacey, 1970; Willis, 2000), nursing (Henderson \& Vesperi, 1995; Roper \& Shapira, 1999; Smyth \& Holmes, 2005), and sport (Adler \& Adler, 1991; Bowles, 2014; Cushion \& Jones, 2006; Parker, 1996). As a research approach, ethnography aims to place specific encounters, events, and understandings into a fuller and more meaningful context (Tedlock, 2000). Culver et al. (2012) argued that there is no simple way of conducting ethnography. Rather ethnographer's experiences are highly variable, and approaches have to be adapted to the particular research problem and setting. Consequently, the

91 ethnographer might operate from a number of different positions during the data collection phase (e.g. insider vs outsider). An insider is situated within the participants' natural setting, and therefore shares some of the participants' experiences (see Atkinson, 2016; Spracklen et al. 2010). In contrast, outsider researchers are not positioned within a specific subculture. For example, Hoeber and Kerwin (2013) described themselves as "outsiders looking in" on the experiences of female sports fans.

In this study, we explore ethnographic work from the position of insider practitioner-researcher. Practitioner-research is defined as a research method carried out by applied practitioners with the aim of further developing our understanding of the social world in which the research was conducted (McLeod, 1999). Over the last decade, insider 
101 practitioner-research has emerged and established itself as a way of understanding and 102 changing organisations (Coghlan, 2007). In health settings (e.g., hospitals, care homes) 103 practitioner-researcher ethnography has advanced knowledge and understanding in 104 relation to managing dual role conflicts (Abdulrehman, 2017; Dixon-Woods, 2018), the 105 insider vs outsider paradoxes (Yeo \& Dopson, 2018), and developing relationships 106 (Holloway \& Galvin, 2016; Ledger, 2010). In sport psychology, practitioner-research has 107 extended our understanding of sports injury and disabilities (Howe, 2003; Shipway \& 108 Holloway, 2016; Smith \& Sparkes, 2016; Sparkes \& Smith, 2009), coach-athlete 109 relationships (Maitland et al., 2015), and the influence of organisational culture on athlete 110 development (Champ et al., 2018; Devaney et al., 2018). Practitioner-research is perhaps

111 the most appropriate method of reducing the gap between research and practice in sport 112 psychology as it encourages applied practitioners to maintain their links with academia, 113 and allows for the publication of models of best practice. Ethnographic practitioner114 research can be described as an art form and provides a new angle to organisational 115 culture and identity studies, inclusive of how a sport psychologist might best operate in 116 elite sport (Ryba et al., 2010). However, to date, there have been limited publications 117 from practitioner-researcher ethnographers operating in elite sport environments, 118 particularly professional football. Consequently, there is currently a significant distance 119 between research that is being disseminated academically and applied practice (Devaney 120 et al., 2018; Lillis, 2008).

121 A more focused exploration of practitioner-researcher ethnography specific to 122 applied sport psychology is important given the significant increase in opportunities for 123 sport psychology practitioners to enter and operate within sports organisations (Nesti et 124 al., 2012). For example, in 2012 the Elite Player Performance Plan (EPPP) formalised the 125 delivery of sport psychology within professional football academies in the UK (Premier 
126 League, 2012). The current paper answers the calls for greater methodological diversity

127 in sport psychology research (Smith \& Sparkes, 2016), and employed insider practitioner-

128 researcher ethnographic methods across three football seasons. The present study

129 emerged in the midst of data collection for my doctoral research project, titled

130 'Psychological Development in Professional Youth Football: An Ethnography of Sports

131 Psychology Practice'. Prior to the official data collection period, I had already worked

132 within this professional football academy as part of an MSc internship and familiarised

133 myself with the working practices of the club. As I transitioned into the practitioner-

134 researcher role, the overriding objective was to explore the impact of organisational

135 culture on the lived experiences of elite youth footballers (see Champ et al., 2018). During

136 the data collection phase, professional and personal issues became a central part of the

137 research, and therefore feature as the focus of this paper. Unlike previous ethnographies

138 in sport psychology, this study reflects on the primary researcher's experiences of

139 occupying a dual position as a sport psychology practitioner-researcher. The in-depth

140 analysis of the extensive period spent as a practitioner-researcher can allow for a deeper

141 understanding of the personal, moral, and ethical challenges that may occur because of

142 this dual role, and inform the career development pathways of other early career

143 ethnographers to enter the field. We aim to critically reflect on the challenges of

144 practitioner-research within professional football

Methodology

\section{Research Paradigm}

This research is situated in a social constructionist, interpretive paradigm. Within

148 a social constructionist perspective (Sparkes \& Smith, 2009), meaning is derived from

149 interpretation, and knowledge is only considered significant in so far as it is meaningful

150 to stakeholders (e.g. reader, researcher, participants) (Smith \& McGannon, 2018). 
151 Furthermore, the methodological perspective was underpinned by a relativist ontology (a

152 belief that there are multiple social realities), a subjectivist epistemology (knowledge is

153 created through social interaction) and a naturalistic set of methodological procedures

154 (data collection occurs in the world of the participants) (Cornbleth, 1990). Ethnographic

155 researchers working within a social constructionist perspective do not approach field

156 settings from an objective position; rather they emphasise that the researchers' own

157 cultural assumptions, personal experiences, and moral stance will shape the research

158 process and outcome (Keane, 2014). Here, we believe that it is important to make the

159 reader aware of the researchers biographical positioning and dual role within the

160 organisation of study.

\section{$161 \quad$ Biographical Positioning}

162 In the present study, the first author (from here onwards, "I"), brought a number

163 of identities to the field. In this paper, identity is defined as "a particular form of social

164 representation that represents the relationship between the individual and others" (Champ

165 et al., 2018, p.13). These 'identities' were a research-based self, a sport psychology

166 practitioner, a young woman, and an avid football fan. My role as a doctoral researcher

167 was hugely important to me as I believed that this was a true test of whether I possessed

168 the skill set to develop a career as an academic. Each of the aforementioned identities

169 were integral in understanding what I observed within the professional football club (e.g.

170 developing relationships, perceptions of academics), how I felt about what I experienced

171 in the club (e.g. moral and ethical conflict), and what is reported on in this study

172 (Cornbleth, 1990).

My role as a doctoral researcher became more important to my identity when I considered the academic experiences of players and staff employed by the organisation under study, which we represent with the pseudonym Tainton Town FC. In comparison 
176 with my university peers and supervisory team, I was an early career academic and novice

177 researcher. In contrast to this, very few members of staff at Tainton Town FC had attended

178 University, and I was the only member of staff to hold a postgraduate degree. Prior to my

179 employment by the club, its organisational members had no previous experiences of

180 academic research, and many commented that they had not heard of the term

181 'practitioner-researcher'. This had a significant impact on my identity within the 182 organisation. For example, I was more conscious of the research ethics (e.g.

183 confidentiality, overt vs covert). We consider this in detail in the results and discussion

184 section of the paper. Furthermore, I was the only female member of staff based at the

185 training ground other than the club chef. This added to the novelty of my position,

186 especially for those who had been at the club for a significant period of their lives (e.g.

187 started out as a youth player aged 9, and progressed into a coaching role upon the 188 termination of their playing career). Because of each of the factors noted above, I believed

189 that I stood out from the other stakeholders at Tainton Town FC.

190 Participants

191 Tainton Town FC is currently one of the 92 UK teams in the English Football 192 League, and consists of over 150 male players, and 50 male support staff. The club takes 193 great pride in the academy set up and its record of producing players that go on to play at 194 the highest level. The focus of Tainton Town FC on the identification and development 195 of young talent is demonstrated by the award of category 2 status by the Premier League 196 (PL) as part of the Elite Player Performance Plan (EPPP).

\section{Data collection}

Data collection took place between September 2014, and May 2017. The occupation of a dual role was a key feature of the study, as I was an insider in the 
organisation rather than on the periphery. Across the duration of the research project, I occupied a dual role as a sport psychology practitioner-researcher within the professional football club. In my role as a sport psychology practitioner, I was responsible for the delivery of sport psychology support to academy players (U9 - U23) and support staff 3-

4 days per week. Methods of support included individual support sessions, group workshops, stakeholder education, and pitch based delivery. I was required to balance this role with conducting the $\mathrm{PhD}$ research project.

In order to address the doctoral research objectives, the data were collected using ethnographic methods, including; observations, reflections, informal interviews, focus groups, and field notes (Atkinson \& Hammersley, 1994). However, in the present study,

210 we draw on the participant observation, reflections, and field notes as these data were

211 directly related to the occupation of a dual role as a sport psychology practitioner-

212 researcher. The purpose of the participant observation was to describe the setting and

213 culture, interactions and activities that took place within the setting, the people that took

214 part in the activities, and meaning of what was observed from the perspective of those

215 who were being observed (Cushion, 2001). I completed the field notes after each occasion

216 I was present in the club, these were descriptive, dated, and recorded key details (location,

217 who was present, activities that took place) (Bryman, 2016). In addition to this, the field 218 notes were a further method of documenting my observations (Spradley, 2016). More

219 specifically, the field notes included events such as confidentiality, interactions with 220 players and support staff, and observations of people's reactions to my research role. 221 Finally, reflexology is the process of critically reflecting on the self as a researcher (Guba \& Lincoln, 2005). Self-reflective writing offers the perspective through which the 223 practitioner-researcher can make sense of their world, and the so-called facts and 224 ideological assumptions that are attached to the position of insider (Denzin, 2002). I 
completed a reflective log (see Smith, 2006) during the data collection, write up, and representation phases of the $\mathrm{PhD}$ research. This was my opportunity to make sense of the situations that I found myself in, but also an opportunity to step back from the data and consider the bigger picture. Here, I documented the influence of the research on me as a practitioner, as a researcher, and a human being (Mulhall, 2003).

Data analysis and representation

The first step of the data analysis was to extract the data documented in the field notes and reflective log (Atkinson and Hammersley 1994). I re-read the field notes and the reflective log and separated the data that related to the process of occupying a dual role as a practitioner-researcher or engaging in the ethnographic research methods. I then conducted a thematic analysis (Braun and Clarke 2016). During this process, data collected from the participant observations are also analysed, as I noted down the observation and my interpretation of it within the field notes. The aim of this was to group the data into themes that were related to the research objective of critically reflecting on

239 the challenges of practitioner-research within professional football. These themes were 240 discussed with research team members, and critical friends, with the aim of increasing 241 data familiarisation (Smith \& McGannon 2018). Following this, themes were refined and 242 those moments that provided the most evocative representation of the theme were chosen.

243 Previous research on the dual role conflict of practitioner-research (Judkins Cohn et al.,

2442014 ; Fan, 2018), and ethical guidelines for the delivery of sport psychology support were used to make sense of the data (British Psychological Society Code of Conduct, 2009;

246 Coghlan, 2007; Gabriel, 2005). In the final step, we presented a series of reflections and

247 field note extracts to illuminate the challenges, and potential use of practitioner-researcher

248 ethnography in elite sport environments. These extracts were selected based on the 249 findings from the thematic analysis (Braun and Clarke, 2016). 
252 guided our approach to research quality. More specifically, throughout the data collection 253 phase, I engaged in member reflections. I discussed critical moments with those at the 254 centre of the event and explored any contradictions or differences in knowing (see Smith $255 \&$ McGannon, 2018). Secondly, I engaged in a process of dialogue with 'critical friends', and research team members following each season of my involvement with Tainton Town

FC. These individuals challenged and questioned my interpretation of the data. We hope that our research is judged on whether it makes a meaningful contribution to the field of sport psychology. We aim to demonstrate that the reflective narratives represented in this study deepens our understanding of how practitioner-researcher ethnography might be experienced in elite sport cultures, particularly professional football. Although these checks like any other validity procedures do not provide access to objective reality, they do add dimensionality and reflexivity to the interpretive work.

\section{Ethical considerations}

The ethical and moral dilemmas of practitioner-researcher ethnography are explained further in the results and discussion section of this paper. Ethnographic

267 researchers have highlighted some of the potential ethical issues that may arise as a result 268 of using ethnographic research methods (Blomberg et al., 2017; Brewer, 2000; Jokinen 269 et al., 2002; Lareau, 2018; Wright \& Schneider, 2010). These include, for example, 270 declaration of research intent, informed consent, and ensuring participant confidentiality.

271 In this study, ethical approval was sought from the relevant University ethics board.

272 Confidentiality was assured for all individuals within the study as no real names were 273 included, and no information that may lead to the identification of any individual has been 
used (Silverman, 2016). In line with Reeves (2010), we attained gatekeeper consent for access to the organisation and the individuals within it. Further consent was attained for the separate elements of the data collection (e.g. interviews, focus groups). In addition to

277 this, parental consent, and informed assent was attained for players under the age of 16.

278 If either a parent or a child did not consent, they were excluded from the study (Hein et al., 2015). However, occupying a dual role as a practitioner-researcher within the organisation raised ambiguity regarding the organisation's anonymity, as it may be possible for readers to identify the organisation of study via other means (MacColl et al., 2005). It was decided that all information would be anonymized as far as possible, and I understood my responsibility to act in the best interests of the participants at all times.

\section{Results and Discussion}

The following section presents a series of separate but interrelated extracts from the reflective log. These field notes and reflective extracts that aim to illuminate my experiences of using ethnographic research methods in professional football. More specifically, the presented narratives are all connected in that they consider the moral, ethical, and personal challenges of occupying a dual role as an early career sport psychology practitioner-researcher within professional football.

\section{Performing an Identity}

Occupying a dual role as a sport psychology practitioner-researcher required me to perform the traditional roles associated with insider ethnography (Atkinson \&

294 Hammersley, 1994). For example, I was required to attend to and report on those events that had a significant impact on stakeholders within the organisation, subtly embed myself within the organisation of study and develop an in-depth understanding of the culture

297 within Tainton Town FC. Managing the balance between my roles and responsibilities as 298 a sport psychology practitioner-researcher, and tolerating the stress of being embedded 
299 within the professional football culture left me feeling conflicted. The following

300 reflection aims to illuminate the frustrations that I experienced in balancing these dual

301 role tensions.

302 December 2015

303 I am psychologically exhausted, we are only 12 months into the practitioner-

304 researcher journey but it feels like a lifetime. Fortunately, today was the last session

305 before the Christmas break, it couldn't come quick enough. Embracing the festive spirit,

306 and following a tough season so far, a group of coaches had arranged for a friendly 11

307 vs 11 combined of staff and players to take place after lunch. Those individuals who were

308 not in one of the teams were invited to sit in the stands. This was a great opportunity for

309 everyone to let their hair down, and take their minds off the upcoming fixtures. That was,

310 apart from me. Staff and players were interacting in a manner that I had not previously

311 witnessed, meaningful conversations kept emerging, and all individuals seemed relaxed.

312 I was enjoying the different dynamic, and the focus on enjoyment as opposed to results.

313 However, I was conscious of my responsibility to 'wear the researcher hat' and keep

314 subtly eavesdropping on the little bursts of conversation. Therefore, I performed the role

315 of practitioner-researcher and refrained from offering my full self to the organisation. In

316 contrast, I was taking mental notes to later add to my data collection. This did not feel

317 right, as a practitioner I believed that I deserved to enjoy the occasion in the same way

318 as the rest of the staff. However, in reality, I was not the same as everyone else, I carried

319 an extra tag, that of the researcher. On this particular day, the researcher tag prevented

320 me from being free.

321 The above reflection is a general representation of how the occupation of a dual

322 role required me to perform particular actions/behaviours associated with the position of

323 a practitioner-researcher (e.g. continual observation). However, these did not always 
324 align with the identity that I felt most comfortable in performing within the social context.

325 For example, the all-consuming data collection methods prevented me from exposing a

326 more relaxed and less attentive side to my personality. Ethnographers (e.g. Fleming,

327 1995; Parker, 1995) have identified the potential for role conflict at different stages of

328 this kind of research, for example negotiating roles and establishing relationships.

329 Judkins-Cohn et al., (2014) suggested that practitioner-researchers need to maintain a

330 balance between their practice and research responsibilities, and establish clear

331 boundaries to reduce the potential for conflict and tension. However, it was not managing

332 the dual role conflict and associated responsibilities that I found most challenging. In

333 contrast, during the three-year data collection phase, my duties as a researcher were at the

334 forefront of my mind and left me feeling constrained. Baillie (1995) noted that being

335 present within an organisation is often a challenge in itself for the researcher and that

336 balancing the occupation of a dual role is complex and multifaceted. We argue that these

337 tensions might be exaggerated in practitioner-research due to the need to prove valuable

338 to the organisation under study, and manage potential conflicts of interest (Parker 1995;

339 McCullough et al., 2015; MacLean and Poole, 2010). My experiences as a practitioner-

340 researcher in this context left me questioning both my identity and sense of belonging as

341 an organisational insider. My lack of experience as an insider practitioner-researcher

342 might have exaggerated these feelings further, as the conflict between my desired and

343 required actions occurred at a time when I was trying to form my own identity as a

344 researcher and applied practitioner (Coffey, 1999). In addition to this, I had limited prior

345 experience of utilising ethnographic research methods, and it was only recently that I was

346 introduced to the concept of ethnographic research by my supervisory team. Ethnographic

347 researchers (e.g. Atkinson \& Hammersley, 1994; Raheim et al. 2016) have argued that

348 the position of an ethnographer (e.g. insider vs outsider) will influence their feelings of 
acceptance within the organisation of study. Originally, these debates considered what it means to be an insider or an outsider in a particular research setting (e.g. Allen, 2004). More recently, researchers have started to consider the potential benefits and challenges surrounding researcher positionality (Dean, 2016). Coghlan and Brannick (2005) suggested that for the insider practitioner-researcher there are often three interlocking challenges, a) the need to develop a closeness to the setting, whilst also being able to create a distance which allows them to view events/situations critically, b) occupying a dual role and managing the ambiguities and conflicts that exist between these, and c) managing organisational politics and developing a future career. Across this research project, I felt that although physically I was present as an insider within the organisation, psychologically I experienced a shifting to and from the different positions. Therefore, in

360 line with Naples (1996), we believe that the distinction between an insider and an outsider is not black and white; rather an individual operates on an insider-outsider continuum. In some cases, this might leave the researcher feeling like an outsider in both roles (Coghlan, 2007). Where each ethnographer is positioned on this continuum will develop and change over time based on their own experiences within and external to the organisation. Coghlan

365 (2007) argued that trying to manage the boundaries of formal and informal hierarchical roles (e.g., roles of colleagueship and friendship) requires total involvement and active commitment. My experiences within the professional football club deeply resonated with this. This was disadvantageous when the research role required the opposite, the ability to be more detached and critically reflective. Re-adjusting my expectations from the

370 research project, reflecting on each experience as a 'learning moment', and learning to accept that in some form ethnography always requires the researcher to engage in roleplaying helped to combat some of the frustrations I experienced in not feeling authentic. 

experienced when Tainton Town FC continued to overlook my role as a researcher within the professional football club. Prior to the start of the research project, I did not anticipate that there would be a downside to my previous time spent within Tainton Town FC as a sport psychology practitioner. Firstly, it had reduced any barriers surrounding my entrance to the organisation, and access to key stakeholders (Cushion, 2001). In addition to this, my value as a sport psychology practitioner helped to reduce some of the organisation's concerns with regards to the research taking place (e.g. contact time with players, interference with normal schedule) (Arber, 2006). However, the contrasting roles of the practitioner-researcher and the reluctance of the professional football club to identify with my role as an academic meant that I faced a series of challenging experiences across the duration of the research. Each of these resulted in me questioning my own values and beliefs. The first extract is taken from the reflective log, and documents an interaction with the U18 manager. Following this, we present a field note extract written six months on from the first encounter, this explores how the U23 manager demonstrated the little value he placed on my role as a researcher.

$390 \quad$ November 2016

What is it going to take for them (the coaches) to take notice of me, the practitioner-researcher? Not just the practitioner, but also the 'other half' of me, the one that gets pushed to one side, the researcher. No matter how hard I try, I just cannot seem to get through to the coaches. Initially, my own insecurities regarding the research

395 project were a hindrance, but I am no longer scared of facing up to challenging questions, bring them on ... at least then it would show Tainton Town FC's consideration of my dual role. Literature suggests that it is beneficial for the researcher if the participant 'forgets'

398 that they are the subject of a scientific study, as it demonstrates that their behaviour is 
399 not influenced by the research. In this case, I didn't believe that the participant's had 400 forgotten that I occupied a dual-role as a researcher, rather than my role was categorised

401 as "not important" because it did not have a direct influence on player development. This

402 lack of willingness to develop an understanding of the research objectives and its 403 associated requirements challenged me from an ethical and personal perspective. Today 404 was just another example of this... I have worked with the U18's manager now for two 405 years as a researcher, and three years as a sport psychology practitioner. On the face of 406 it, our relationship is good, until it comes to my role as a researcher. I was sat in the 407 office typing up field notes on my laptop when he approached me and asked, "so what's 408 this thing you're doing at uni again?". I was a little embarrassed at the nature of his 409 question, but saw this as an opportunity to turn a corner. Firstly, I reminded him of 410 previous conversations about the research and continued to explain what the purpose of 411 this was in relation to the club. At this point he interrupted, "yeah yeah, all that stuff is 412 beyond me, as long as you keep doing what you do with the lads that's all that matters". 413 This reinforced my previous perception of their lack of interest, and ignorance of the 414 research project. I felt deflated, and was on the brink of giving up. I didn't know what 415 else I could do to change their perceptions."

416 As noted previously, the following extract occurred six months later and describes an 417 interaction with the head coach from a different age group. It is hoped that this field note 418 extract demonstrates that the attitudes/perceptions of coaches were consistent across the 419 age groups and over time.

$420 \quad$ Field note extract (May 2017)

$421 \quad$ I had arranged with the U23 manager a number of weeks ago that I would use today's session to conduct end of season interviews with the U23 players. This aligned 423 with one of the broader research objectives (to explore the efficacy of a psychological 
425 Town FC). However, only minutes before I was supposed to conduct my first interview, the U23 manager approached me and mentioned that if it was only interviews for my research project then he wanted them for an extra fitness session instead. He explained that this was because they had performed poorly and displayed a poor professional approach in the last few games of the season. The manager stated, "Your stuff can wait can't it, it's only for your uni course it isn't the proper psychology stuff is it?" disinterest of my role as a researcher. This pattern of events continued across the longitudinal duration of the research despite continued attempts to alter perceptions and gain acknowledgement of my dual role. For example, feeding back on the findings of the research at the end of each season to the full-time members of staff within the organisation, and questioning the efficacy of the research process with key stakeholders. As an early career researcher, experiences such as the above posed a significant threat to my researcher identity, and resulted in me questioning my own moral and ethical principles. In the first instance the reaction of Tainton Town FC to the research resulted

440 in me loathing this aspect of my role (Coffey \& Atkinson, 1996). For example, I was 441 reluctant to be seen on a computer, or making notes during a training session/ around the training ground. In addition to this, I believed that I was not capable of conducting this kind of research, and was concerned about how the participants truly felt about taking 444 part in the study. However, over time I grew frustrated by and eventually desensitized to 445 their comments. I was also concerned by the lack of acknowledgement of the research by 446 key stakeholders, and believed that it raised a number of ethical questions. During the 447 university ethics procedure there was a clear focus from the ethics board on the need to 448 ensure that all participants were explicitly aware of the nature of the research project. 
449 Judkins-Cohn et al. (2014) argued that the relationship between the researcher and the

450 participants is imperative in relation to informed consent. For example, the power

451 dynamic between the practitioner and research must be considered to ensure that the

452 participants make their decisions based on free will as opposed to feeling obliged. The

453 ignorance of my research role increased my anxiety during the data collection phase, and

454 often resulted in me feeling that there was a tension between what I was experiencing and

455 what I 'should' be experiencing, and the challenges that I was facing (See Dixon-Woods

456 et al., 2007) Furthermore, I was conscious of the potential implications for the write up

457 and dissemination of the findings. In the hope of maintaining high ethical standards, I

458 made a conscious effort to remind the participants of the research process on appropriate

459 occasions during the data collection and write up phases. However, I was also careful not

460 to over-remind the participants to the extent that it influenced their behaviour in the

461 research setting (Coffey \& Atkinson, 1996). The American Nurses Association (ANA,

462 2001) identifies that dual role practitioners need to demonstrate respect for the

463 participant's inherent dignity and worth; and protection for their health and safety. During

464 this time, I sought the support of my research team, and advice of a university-based

465 ethnographers club to ensure that I acted in the best interests of the participants. Bjorkman

466 (2005) described the personal struggles and identity questioning that he faced as a

467 consequence of being a practitioner first and then adopting the secondary role of the

468 researcher at a later stage. On reflection, we would suggest that I found this deeply

469 problematic because of my level of experience in using ethnographic research methods,

470 and anxieties in ensuring I adhered to the university research ethics guidelines (Dixon-

471 Woods et al., 2007). As a young female practitioner I was positioned as 'naturally' less

472 competent in sport-related matters (see Kilty, 2006) and these discursive practices were

473 reproduced within the organisation, leaving me feeling unconfident and reliant on my 
academic supervisors. However, as practitioners become more experienced they become

475 more flexible in their approach, are able to constructively critique their practice, and 476 become less reliant on their supervisor. Schon (1995) supported this viewpoint and 477 suggested that any insider research is messy, and problems can arise. However, as the 478 insider researcher gains fieldwork experience and has to make challenging decisions they 479 become more capable of handling the difficulties associated with ethnographic practitioner-research.

One potential explanation for the behaviour of the coaches within Tainton Town

FC is the organisational culture within professional football. Sport researchers (e.g. Cushion, 2001; Kelly \& Waddington, 2006) have noted that professional football clubs are often sceptical of those with a university background, and closed to 'outsiders'.

485 Tainton Town FC had not previously collaborated with a university researcher, and therefore, it might be suggested that the ignorance shown to my research project could be due to scepticism towards academics, and a lack of understanding of research. Given my reliance on Tainton Town FC for the successful completion of the research project, I was conscious of the need to protect my status within the organisation. Similar to what was

490 reported by Parker (1995), I was careful about how I portrayed myself in the football club.

491 For example, I would spend limited time on my laptop in order to avoid being viewed as an academic. Here lay the conflict between wanting to remind the participants of the research project, and needing to align my own actions/behaviours with the dominant

494 behaviours of the organisation in order to maintain my position in the club. Secondly, it 495 might be suggested that Tainton Town FC were disinterested in my role, as it did not have an immediate impact on the development of players. Professional football is a results497 oriented business (Nesti \& Sulley, 2014). Kelly and Waddington (2006) noted that any 498 individual who does not demonstrate their value is likely to be frozen out and eventually 
499 rejected from the organisation. In line with this, it might be argued that although

500 stakeholders situated within Tainton Town FC were aware of the research they chose to

501 direct their effort and attention towards my role as a practitioner, as it was this that had a

502 direct impact on the daily lives of academy players. Given the hegemonic culture of

503 professional football (e.g. dominance of masculinity, displays of power, the requirement

504 to conform to authority, ruthlessness) (Gearing, 1999), and its reluctance to change we

505 suggest that early career practitioner-researchers who enter this social context in the

506 upcoming years are likely to share a similar research experience.

\section{Confidentiality}

508 The final reflective narratives illuminate the issue of practitioner-researcher

509 confidentiality within Tainton Town FC. Confidentiality first arose as a potential issue

510 during the ethics application, at this stage my concerns related to maintaining the

511 anonymity of both the organisation, and the participants within the club. Following in-

512 depth discussions with my research team, and the university ethics board we concluded

513 that although we could not guarantee the anonymity of Tainton Town FC, the anonymity

514 of individuals within the club could be ensured with pseudonyms and the alteration of

515 any identifying details. Despite this, I had to make a number of challenging decisions

516 during the write-up phase of the study, which often left me feeling a sense of betrayal to

517 individuals that I had developed meaningful relationships with. Within this subsection,

518 we present two reflective extracts. The first reflection details an event that occurred as I

519 was nearing the end of my time with Tainton Town FC and relates specifically to the

520 anxieties that I faced when writing up my experiences. The second reflection explores the

521 challenges that I faced in introducing confidentiality as an important aspect of my

522 practitioner-researcher role within Tainton Town FC.

$523 \quad$ February 2017 
524 As I entered Tainton Town FC this morning, I was approached by Ted (youth team

525 scholar). He was clearly in a state of panic and proceeded to tell me that his father was

526 in intensive care after suffering a heart attack the previous evening. The player had made

527 the choice to get the bus into training as usual despite his dad's condition. He explained

528 that he didn't want the event or an absence to affect the coach's decision on whether his

529 contract would be renewed or terminated later that month. I felt proud that the player

530 had approached me, and believed that this signified the strength of our relationship.

531 Although Ted had made me aware of the situation, he was reluctant for any other member

532 of staff in the club to know of his circumstances. To me, this was deeply concerning in

533 that it further demonstrated the negative impact of the professional football culture that

534 I had been exposed to during the data collection. This event had clear implications for

535 future applied practice in sport psychology, for example the importance of a holistic

536 approach to player support inclusive of counselling skills. However, this was a pivotal

537 moment in Ted's life, and it had taken a lot of trust for him to choose to share this event

538 with me. Therefore, I was now grappling with an incredibly difficult decision. If I choose

539 to include this player's narrative within my thesis am I betraying his trust. I doubt in the

540 moment that he approached me he considered my role as a researcher. He found himself

541 in a crisis situation, and sought my advice as a sport psychology practitioner. Anonymity

542 is considered central in both practitioner and researcher ethics. However, if I choose not

543 to publish the data due to the highly personal and unpredicted nature of the event am I

544 adhering to my role as a researcher to meet a number of research objectives? I feel

545 conflicted, torn, and unsure where my loyalties lie.

546 The following reflection offers a more holistic consideration of how coaches viewed

547 confidentiality within Tainton Town FC.

548 Confidentiality 
549 I am stood in the education suite about to deliver a presentation to around 15 members

550 offull-time staff. These included; physios, sports scientists, coaches (U11-U21), assistant

551 manager, 1st team manager, and academy director. The aim of the presentation was to

552 educate coaches on the importance of confidentiality in sport psychology. Although

553 nervous, I spoke confidently, fully believing that the staff would understand the

554 importance of the workshop. I finished the slide and just as I was about to move onto the

555 next, Joe (U21 manager) spoke: "I don't agree with all this confidentiality malarkey,

556 that's not the way it is around here"... I gulped and slowly lifted my head to look at the

557 reaction of the other staff. To my dismay, they nodded in agreement. In an attempt to take

558 the pressure off myself, I asked Joe what he meant. However, his response only confirmed

559 that his opinion was strong. He stated, "The staff here have worked with each other long

560 enough to know that everyone needs to be kept in the loop about everything, you do your

561 job, but if we don't know how players are mentally, we can't pick the strongest team"

562 My heart rate rose again. I could not cave in and agree, it would be morally, and ethically

563 wrong. Nevertheless, this guy is important, he's been at the club nearly 15 years, and

564 what he says goes. I stepped back, took a breath and went for it... I asked the staff to

565 remember the days they played, or put themselves into the players' shoes. I gave them a

566 scenario and asked them to discuss and decide whether I should take the issue to the

567 coach. Small-scale conversations started to emerge. For now, I could recompose myself,

568 reign in my emotions, and aim to take back control of the discussion. In a bid for some

569 positivity, I asked if anyone thought the example issue should be kept confidential. The

570 U16 coach spoke, he was an ex-player and reinforced my belief that confidentiality would

571 be important if I was to be effective. More confident in my stance, I rounded up the

572 conversation and asked what the thoughts were moving forward, although Joe started

573 with "Even though I don't agree" he finished with "you make a judgement on what needs 

was not positive, but it was a lot less negative than his previous answers.

577 perspective. Throughout the duration of the doctoral research, the conflict between my 578 role as a researcher and sport psychology practitioner was evident. Alongside the 579 completion of the research project, I was engaging in professional training with the British 580 Association of Sport and Exercise Sciences (BASES), where the importance of maintaining confidentiality was emphasised on a number of occasions. Furthermore, both BASES and the British Psychological Society (BPS) have association codes on the importance of confidentiality, with the BPS stating that practitioners have a moral duty and obligation to adhere to this code (BPS Code of Conduct, 2009, p.10). Confidentiality was also highlighted during the university ethics process from a research perspective; therefore, situations such as the above required me to question my own stance on the role of a practitioner-researcher. Davis (1997) explored a similar conflict in ethnographic nursing research. His findings highlighted that nursing practice is primarily dedicated to

589 patient care and is governed by a strict ethical code of practice. However, at times this 590 code was at odds with the requirements of ethnographic research methods. This runs 591 parallel with sport psychology which is primarily about empathy and client care, and the BPS, BASES, AASP have codes of conduct on ethical conduct. However, these are at 593 odds with daily practices within professional football (e.g. results-oriented, volatile, 594 ruthless), and the use of ethnographic research methods (e.g. confidentiality, the 595 publication of data). I was writing about highly personal case studies that were critical 596 moments for those at the centre of the experience. Professionally I questioned whether 597 this was ethical, but also personally I often wondered how I would have reacted if I was 598 one of the participants whom a researcher had 'told the story' of. Despite these doubts, 
ethnographic researchers have identified the importance of the researcher making 'good'

600 decisions regarding the write-up and publication of the data. Fleming (1995) suggested

601 that the responsibility lies with the researcher to ensure that the best interests of the

602 participants are taken into consideration when disseminating the data. Furthermore,

603 Coghlan (2007) noted that gaining access, using data, and disseminating and publishing

604 data are intensely political acts that need to be attentively, intelligently, reasonably, and

605 responsibly managed. However, there is a lack of specific information regarding what

606 this actually means in practice.

607 Norris (1993) identified three options for dealing with data that might result in 608 unpleasant memories for the participants (in this case the players and staff within the 609 organisation). The first option is to report the data to an appropriate body or lodge a 610 complaint. However, we rejected this as it breaches confidentiality, and might spoil the 611 field for future enquiry. Secondly, Norris (1993) suggested that the research could be 612 abandoned, or at least the data not included. At times, this was the option that my feelings 613 about the research most closely resonated with. As a research team, we rejected this 614 approach as it encourages the manipulation of data, and might even force the researcher 615 to leave the field of enquiry. The final approach is to treat it like any other data and publish 616 accordingly. The final choice was deemed most appropriate as it allowed me to keep the

617 promises of the research bargains and maintain the integrity of the data, whilst continuing 618 in the field. With more experience of conducting ethnographic practitioner-research, I 619 might have been more comfortable with some of the conflicts and tensions that arose 620 during the data collection and write-up, and better able to make difficult decisions as opposed to relying on the guidance of my supervisory team. 
624 engagement with the organisation and its key stakeholders that I developed an 625 understanding of the subtle changes in participant's actions and behaviours, and the 626 meaning that was attached to these. Furthermore, developing a trusting relationship with

627 individuals took a significant time-period due to the closed nature of the professional 628 football club, and my expertise in a discipline that the club had not previously been 629 exposed to. We believe that being embedded within Tainton Town FC for over 1500 630 hours per season meant that those within the organisation developed an in-depth 631 understanding of my personal characteristics and motives in the organisation, and 632 behaved more naturally.

\section{General Discussion}

In this article, we explored the use of practitioner-researcher ethnography in one professional football club and illustrated some of the methodological challenges that might be experienced as a result of this dual role occupation. Although previous research

637 has explored the potential for ethnography in applied sport psychology (e.g. Krane \& Baird, 2005; Smith \& McGannon, 2018), there has been a lack of published practitionerresearcher ethnographies conducted in sport, especially professional football. This is

640 limited in that ethnographic researchers have not considered how best to conduct 641 practitioner-research in a sporting context, especially from the perspective of an early career practitioner-researcher.

In this paper, we have highlighted the challenges faced by a novice practitioner-

644 researcher (e.g. emotional impact, identity development, moral and ethical questioning).

645 Furthermore, our study extends current understandings of the challenges (personal, 646 ethical) that might be experienced as a function of occupying a dual role, and aims to 647 enhance other practitioner's awareness prior to entering the field. This is important when 648 we consider the increasing opportunities for sports psychologists to gain entrance to and 
649 operate within professional football clubs, and future potential to diminish the gap

650 between academic research and applied practice (Lillis, 2008). In addition to the above,

651 many current ethnographies in sport were conducted across the duration of one season

652 (e.g. Cushion, 2001; Parker, 1995). In comparison, our research was conducted across a

653 three-year period where I was positioned as an 'insider' within Tainton Town FC. The

654 extended duration of our research resulted in the identification of a number of 655 practitioner-researcher challenges that have not been discussed previously from the 656 position of an organisational insider in sports literature (for example, threats to 657 authenticity, acceptance of academics in professional football, and managing 658 confidentiality). Furthermore, over the duration of the study, there was a significant 659 period of organisational change (e.g. $1^{\text {st }}$ team manager, assistant manager, $660 \mathrm{U} 14 / \mathrm{U} 16 / \mathrm{U} 18 / \mathrm{U} 23$ coaches, all sports science and medicine team departed Tainton Town 661 FC). Despite, the significant transition in personnel my experiences as a practitioner662 researcher remained consistent. The limited impact of the organisational change further 663 solidified my belief that the cultural characteristics of professional football transcend 664 individual actors within the clubs, and shaped the actions and attitudes of staff members 665 towards the research. This kind of holistic understanding of practitioner-research is 666 important for developing appropriate education and support mechanisms for future 667 ethnographic practitioner-researchers.

668 Consequently, we suggest that a range of support mechanisms are essential for the 669 ethnographic practitioner-researcher in helping them to deal with researcher emotionality, 670 and challenging ethical dilemmas. Firstly, we believe that the introduction of ethnography 671 clubs both within and external to universities would be beneficial in supporting 672 practitioner-researchers on their research journey. For example, ethnographers with 673 different levels of experience, and areas of expertise might come together at regional hubs 
674 to meet and share their experiences of using ethnographic research methods. With

675 particular relation to this study, a neophyte practitioner-researcher support group would

676 be beneficial. In addition to this, training and educational support might be offered to

677 practitioner-researchers and their supervisors at the start of their research journey. For 678 example, ethnographic experts may run workshops or webinars for practitioner679 researchers on the complexities of occupying a dual role. Practitioner-research is a 680 relatively new ethnographic space in sport psychology, in that there is limited research 681 from neophyte sport psychologists working in professional football clubs who occupy the 682 dual role as a researcher. Therefore, adding sport psychology course content on 683 organisational culture and identity development, power and politics might provide novice 684 practitioner-researchers with more interpretive resources so that they can make sense of 685 their lived experiences in a more constructive manner. This paper has developed our 686 knowledge and understanding of some of the challenges that individuals might face in 687 this particular setting. Finally, we believe that by encouraging practitioner-researchers to 688 develop a clear sense of self might facilitate their successful navigation through the 689 challenging research journey. Often the only people who can do this type of research are 690 doctoral students as they can give up the time to really embed themselves. Therefore, the 691 practical implications that we have proposed should focus on this population.

\section{Limitations and Future Research Directions} We acknowledge that we have not attained the perspective of Tainton Town FC 694 on my occupation of a dual role as a sport psychology practitioner-researcher. This could 695 be addressed by studies that explore the organisations perspective on how practitionerresearchers might operate within elite sport using focus groups and interviews. This is

697 only the view of one individual. It is important to note that other practitioner-researchers 698 might not have experienced or reflected on their experiences in the same way as me (Van 
699 Maanen, 2011). For example, we believe that a more experienced practitioner-researcher

700 or ethnographic researcher might not have experienced the same uncertainty and tension

701 if the coaches did not acknowledge their role, rather they might see this as beneficial, a

702 demonstration that participants were not shaped by the research. In addition to this, only

703 one organisation was studied which might not be representative of the culture of other

704 elite sports environments.

705 To date, only a very small number of practitioner-researcher ethnographies (e.g.

706 Devaney et al., 2018) have been conducted in elite sport. Further studies from other

707 practitioner-researchers within elite sport would help us to better understand whether the

708 findings of this study lie in isolation, or if they are generalizable across this social context.

709 In conclusion, our findings highlight the challenges that practitioner-researchers might

710 face when operating in elite sport environments that are often sceptical of academics

711 (Nesti et al., 2012), and driven by performance (Nesti \& Sulley, 2014). A clearer

712 understanding of the challenges that practitioner-researchers face in other high-

713 performance cultures may inform the development of more effective education and

714 support methods.

\section{Conclusion}

716

The present study sought to reflect on the challenges of practitioner-research

717 within professional football, thereby deepening our understanding of how to manage the

718 dual role tensions of practitioner-researcher ethnography. Our analytic work resulted in

719 identifying three key challenges: threats to identity, acceptance of academics in

720 professional football, and managing confidentiality. Based on this three-year

721 ethnography, we have shown that practitioner-research methods are demanding,

722 emotional, and hugely challenging. More specifically, practitioner-researchers are

723 required to make pressurised decisions (e.g. reporting on data) in the best interests of the 
724 participating organisation and the associated academic field, which often have conflicting

725 ideals. Furthermore, if practitioner-researchers fail to demonstrate their value in both the

726 practitioner and the researcher role they risk being deprived of their position within an

727 organisation. Therefore, a practitioner-researcher should possess a high level of self-

728 awareness, and an appropriate level of support and guidance should be available

729 throughout (ethnographers clubs, strong supervisor relationship, and peer support).

730

731

References

732 Abdulrehman, M. S. (2017). Reflections on native ethnography by a nurse researcher.

733 Journal of Transcultural Nursing, 28(2), 152-158.

734 Adams, T. E., Ellis, C., \& Jones, S. H. (2017). Autoethnography. The International

735 Encyclopedia of Communication Research Methods, 1-11.

736 Adler, P. A. \& Adler, P., 1991. Blackboards and Blackboards: College Athletes and Role

737 Engulfment. New York: Columbia University Press

738 Allen, D. (2004). Ethnomethodological insights into insider-outsider relationships in

739 nursing ethnographies of healthcare settings. Nursing inquiry, 11(1), 14-24.

740 American Nurses Association Code of Ethics for Nurses with Interpretive Statements.

741 2001.Availablefrom: http://www.nursingworld.org/MainMenuCategories/EthicsStandar

742 ds/Tools-You-Need/Code-of-Ethics.pdf.

743 Andersen, M. B., (2005). 'Yeah I work with Beckham': Issues of confidentiality, privacy

744 and privilege in sports psychology service delivery. Sport and Exercise Psychology

745 Review, 1(2), 5-13.

746 Arber, A., (2006). Reflexivity: A challenge for the researcher as practitioner?. Journal of

$747 \quad$ Research in Nursing, 11(2), 147-157. 
Atkinson, M., 2016. Ethnography. In Routledge handbook of qualitative research in sport

749 and exercise (pp. 71-83). Routledge.

750 Atkinson, P. \& Hammersley, M., (1994). Ethnography and participant observation. In:

751 Handbook of qualitative research. Thousand Oaks, California: Sage, 248-261

752 Baillie, L. (1995). Ethnography and nursing research: a critical appraisal. Nurse

753 Researcher, 3(2), 5-21.

754 Bensimon, E., Polkinghorne, D., Bauman, G. \& Vallejo, E., (2004). Doing research that 755 makes a difference. The Journal of Higher Education, 75(1), 104-126

756 Bjorkman, H. and Sundgren, M. (2005), "'Political entrepreneurship in action research:

757 learning from two cases", Journal of Organizational Change Management, 18, 5, 399758415.

759 British Psychological Society, (2009). Code of Ethics and Conduct, Ethics Committee, 760 https://www1.bps.org.uk/system/files/user-

761 files/Division $\% 20$ of $\% 20$ Clinical $\% 20$ Psychology/public/Code $\% 20$ of $\% 20$ Ethics $\% 20$ and $762 \% 20$ Conduct $\% 20 \% 282009 \% 29 . p d f$

763 Blomberg, J., Giacomi, J., Mosher, A., \& Swenton-Wall, P. (2017). Ethnographic field 764 methods and their relation to design. In Participatory Design (pp. 123-155). CRC Press.

765 Bowles, H., 2014. Days in the Dirt: An Ethnography on Cricket and Self. Cardiff: Cardiff

766 Metropolitan University

767 Braun, V., Clarke, V., \& Weate, P. (2016). Using thematic analysis in sport and exercise

768 research. Routledge handbook of qualitative research in sport and exercise, 191-205.

769 Brewer, J.D. (2000). Ethnography. Buckingham: Open University Press

770 Brydon-Miller, M., Greenwood, D., \& Maguire, P. (2003). Why action research?.

771 Bryman, A. (2016). Social research methods. Oxford university press. 
772 Champ, F.M., Nesti, M.S., Ronkainen, N.J., Tod, D.A \& Littlewood, M.A (2018). An

773 Exploration of the Experiences of Elite Youth Footballers: The Impact of Organisational

774 Culture. Journal of Applied Sport Psychology, DOI: 10.1080/10413200.2018.1514429

775 Coffey, A. \& Atkinson, P., (1996). Making sense of qualitative data: Complementary

776 research strategies. Thousand Oaks, California: Sage

777 Coghlan, D. (2007). Insider action research: Opportunities and challenges. Management

$778 \quad$ Research News, 30(5), 335-343.

779 Coghlan, D., \& Brannick, T. (2005). Doing Action research in your organization. London:

$780 \quad$ Sage

781 Cornbleth, C. (1990). Curriculum in context. London and New York: Falmer.

782 Corrigan, P., 1979. Schooling the Smash Street Kids. London: Macmillan Education Ltd.

783 Coy, M. (2006). This morning I'm A researcher, this afternoon I'm an outreach worker:

784 Ethical dilemmas in practitioner research. International journal of social research

785 methodology, 9(5), 419-431.

786 Culver, D. M., Gilbert, W., \& Sparkes, A. (2012). Qualitative research in sport

787 psychology journals: The next decade 2000-2009 and beyond. The Sport

788 Psychologist, 26(2), 261-281.

789 Cushion, C., (2001). The coaching process in professional youth football: An

790 ethnography of practice. London: Brunel University School of Sport and Education PhD

791 Theses.

792 Cushion, C. \& Jones, R. L., 2006. Power, Discourse, and Symbolic Violence in

793 Professional Youth Soccer: A Case of Albion Football Clun. Sociology of Sport, 142-161.

794 Davis, R., 1997. Community caring: An ethnographic study within an organizational

795 culture. Public Health Nursing, 14(2), 92-100. 
796 Dean, J. (2016). Walking in their shoes: utilizing go-along interviews to explore

797 participant engagement with local space. In Practicing Qualitative Methods in Health 798 Geographies (pp. 131-148). Routledge.

799 Denzin, N. K. (2002). The interpretive process. The qualitative researcher's companion, $800 \quad 349-366$.

801 Devaney, D. J., Nesti, M. S., Ronkainen, N. J., Littlewood, M., \& Richardson, D. (2018).

802 Athlete Lifestyle Support of Elite Youth Cricketers: An Ethnography of Player Concerns

803 Within a National Talent Development Program. Journal of Applied Sport Psychology, $804 \quad 1-21$.

805 Dixon-Woods, M. (2003). What can ethnography do for quality and safety in health care?

806 BMJ Quality \& Safety, 12(5), 326-327.

807 Dwyer, S. C., \& Buckle, J. L. (2009). The space between: On being an insider-outsider 808 in qualitative research. International journal of qualitative methods, 8(1), 54-63.

809 Fan, Y. C. (2018). Reflections on Practitioner Research: A Case Study in EFL Reading 810 Instruction. European Journal of English Language Teaching.

811 Fetterman, D. M. (Ed.). (2010). Ethnography: Step-by-step (Vol. 17). Sage.

812 Fleming, (1995). 'Home and Away': Sport and South Aisan Male Youth. Aldershot: 813 Avebury.

814 Gabriel, L. (2005). Speaking the unspeakable: The ethics of dual relationships in 815 counselling and psychotherapy. Routledge.

816 Gearing, B. (1999). Narratives of Identity among former professional footballers in the

817 United Kingdom. Journal of Aging Studies, Volume 13, 43-58.

818 Gough, B. (2016) Reflexivity in qualitative psychological research, The Journal of 819 Positive Psychology, 12:3, 311-312 
820 Guba, E. G. \& Lincoln, Y. S., (2005). Paradigmatic controversies, contradictions, and 821 emerging confluences. In: The Sage handbook of Qualitative Research. Thousand Oaks, 822 California: Sage, pp. 191-235

823 Hein, I. M., De Vries, M. C., Troost, P. W., Meynen, G., Van Goudoever, J. B., \& 824 Lindauer, R. J. (2015). Informed consent instead of assent is appropriate in children from 825 the age of twelve: Policy implications of new findings on children's competence to 826 consent to clinical research. BMC medical ethics, 16(1), 76.

827 Henderson, N. J. \& Vesperi, M. D., 1995. The Culture of Long Term Care: Nursing Home 828 Ethnography. United States of America: Greenwood Publishing Group.

829 Hoeber, L., \& Kerwin, S. (2013). Exploring the experiences of female sport fans: A 830 collaborative self-ethnography. Sport Management Review, 16(3), 326-336.

831 Holloway, I. and Galvin, K., 2016. Qualitative research in nursing and healthcare. John 832 Wiley \& Sons.

833 Holstein, J. A., \& Gubrium, J. F. (Eds.). (2013). Handbook of constructionist research. 834 Guilford Publications.

835 Howe, D., 2003. Sport, professionalism and pain: Ethnographies of injury and risk. 836 Routledge.

837 Jokinen, P., Lappalainen, M., Meriläinen, P., \& Pelkonen, M. (2002). Ethical issues in 838 ethnographic nursing research with children and elderly people. Scandinavian Journal of 839 Caring Sciences, 16(2), 165-170.

840 Judkins-Cohn, T. M., Kielwasser-Withrow, K., Owen, M., \& Ward, J. (2014). Ethical 841 principles of informed consent: Exploring nurses' dual role of care provider and 842 researcher. The Journal of Continuing Education in Nursing.

843 Keane, W. (2014). Affordances and reflexivity in ethical life: An ethnographic stance. 844 Anthropological Theory, 14(1), 3-26. 
845 Kelly, S. \& Waddington, I., (2006). Abuse, intimidation and violence as aspects of 846 managerial control in professional soccer in Britain and Ireland. International Journal for 847 the Sociology of Sport, 41(2), 147-164.

848 Kilty, K., 2006. Women in coaching. The sport psychologist, 20(2), pp.222-234.

849 Krane, V. \& Baird, S., (2005). Using Ethnography in Applied Sports psychology. Journal 850 of Applied Sports psychology, 17(2), 87-107.

851 Lacey, C., 1970. High Town Grammar, Manchester: Manchester University.

852 Lareau, A. (2018). Journeys through ethnography: Realistic accounts of fieldwork.

853 Routledge.

854 Larsen, J. (2018). Commuting, exercise and sport: an ethnography of long-distance bike 855 commuting. Social \& Cultural Geography, 19(1), 39-58.

856 Ledger, A., 2010. Exploring multiple identities as a health care ethnographer. 857 International Journal of Qualitative Methods, 9(3), 291-304.

858 Levin, M., \& Greenwood, D. (2001). Pragmatic action research and the struggle to 859 transform universities into learning communities. Handbook of action research:

860 Participative inquiry and practice, 103-113.

861 Lillis, T. (2008). Ethnography as method, methodology, and "Deep Theorizing" closing 862 the gap between text and context in academic writing research. Written 863 communication, 25(3), 353-388.

864 Maitland, A., 2012. A study to investigate newly-qualified nurses' experiences of 865 preceptorship in an acute hospital in the south-east of England. University of Surrey: 866 Unpublished $\mathrm{PhD}$ Thesis.

867 MacColl, I., Cooper, R., Rittenbruch, M., \& Viller, S. (2005, November). Watching 868 ourselves watching: Ethical issues in ethnographic action research. In Proceedings of the 869 17th Australia conference on Computer-Human Interaction: Citizens Online: 

Interest Group (CHISIG) of Australia.

872 MacLean, M., \& Poole, G. (2010). An Introduction to Ethical Considerations for Novices

873 to Research in Teaching and Learning in Canada. Canadian Journal for the Scholarship

874 of Teaching and Learning, 1(2), 7.

875 Maitland, A., 2012. A study to investigate newly-qualified nurses' experiences of 876 preceptorship in an acute hospital in the south-east of England. University of Surrey:

877 Unpublished $\mathrm{PhD}$ Thesis.

878 McCullough, M. B., Chou, A. F., Solomon, J. L., Petrakis, B. A., Kim, B., Park, A. M., 879 ... \& Rose, A. J. (2015). The interplay of contextual elements in implementation: an 880 ethnographic case study. BMC health services research, 15(1), 62.

881 McGannon, K.R., \& Smith, B. (2015). Centralizing culture in cultural sport psychology 882 research: The potential of narrative inquiry and discursive psychology.

883 McLeod, J., (1999). Practitioner research in counselling. Sage

884 Mitchell, T. O., Nesti, M., Richardson, D., Midgley, A. W., Eubank, M., \& Littlewood, 885 M. (2014). Exploring athletic identity in elite-level English youth football: a cross886 sectional approach. Journal of sports sciences, 32(13), 1294-1299.

887 Morill, C., \& Fine, A. (1997). Ethnographic Contributions to Organizational Sociology.

$888 \quad$ Sociological Methods \& Research, 25(4), 424-451

889 Mulhall, A. (2003). In the field: notes on observation in qualitative research. Journal of 890 advanced nursing, 41(3), 306-313.

891 Naples, N. A., (1996). A feminist revisiting of the insider/outsider debate: The "outsider 892 phenomenon" in rual Iowa. In: Reflexity and Voice. London: Sage. 
893 Nesti, M., \& Littlewood, M. (2011). Making your way in the game: Boundary situations

894 in England's professional football world. Critical essays in applied sport psychology, $895 \quad 233-250$.

896 Nesti, M. \& Sulley, C., (2014). Youth Development in Football: Lessons from the world's

897 best academies. London: Routledge

898 Nesti, M., Littlewood, M., O’Halloran, L., Eubank, M., \& Richardson, D. (2012). Critical 899 moments in elite premiership football: who do you think you are?. Physical Culture and 900 Sport. Studies and Research, 56(1), 23-32.

901 Norris, C., (1993). The truth about postmodernism. Oxford: Basil Blackwell

902 Parker, A., (1995). Great Expectations: Grimness or Glamour? The Football Apprentice 903 in the 1990s. The Sport Historian, 107-126.

904 Ragin, C. C. (2014). The comparative method: Moving beyond qualitative and 905 quantitative strategies. Univ of California Press.

906 Råheim, M., Magnussen, L. H., Sekse, R. J. T., Lunde, Å., Jacobsen, T., \& Blystad, A. 907 (2016). Researcher-researched relationship in qualitative research: Shifts in positions and 908 researcher vulnerability. International journal of qualitative studies on health and well909 being, 11(1), 30996.

910 Reason, P., \& Bradbury, H. (Eds.). (2001). Handbook of action research: Participative 911 inquiry and practice. Sage.

912 Reeves, C. L. (2010). A difficult negotiation: Fieldwork relations with gatekeepers.

913 Qualitative Research, 10(3), 315-331.

914 Roper, J. \& Shapira, J., 1999. Ethnography in Nursing Research. London: Sage 915 Publications. 
916 Ryba, T. V., Stambulova, N. B., Si, G., \& Schinke, R. J. (2013). ISSP position stand:

917 Culturally competent research and practice in sport and exercise psychology.

918 International Journal of Sport and Exercise Psychology, 11(2), 123-142.

919 Schon D. (1995) The new scholarship requires a new epistemology. Change, 27, 26-34

920 Scott-Hamilton, J., Schutte, N. S., \& Brown, R. F. (2016). Effects of a mindfulness

921 intervention on sports-anxiety, pessimism, and flow in competitive cyclists. Applied

922 Psychology: Health and Well-Being, 8(1), 85-103.

923 Shipway, R., \& Holloway, I. (2016). Health and the running body: Notes from an

924 ethnography. International Review for the Sociology of Sport, 51(1), 78-96.

925 Silverman, D. (Ed.). (2016). Qualitative research. Sage.

926 Simon, G. M. (2009). The soul freed of cares? Islamic prayer, subjectivity, and the

927 contradictions of moral selfhood in Minangkabau, Indonesia. American Ethnologist, $928 \quad 36(2), 258-275$.

929 Smith, D. E. (Ed.). (2006). Institutional ethnography as practice. Rowman \& Littlefield.

930 Smith, B. (2013). Disability, sport and men's narratives of health: A qualitative study.

931 Health psychology, 32(1), 110.

932 Smith, B., \& McGannon, K.R. (2018). Developing rigor in qualitative research: problems

933 and opportunities within sport and exercise psychology. International Review of Sport 934 and Exercise Psychology, 1-22

935 Smith, B., \& Sparkes, A. (2016). Routledge handbook of qualitative research in sport and 936 exercise. London: Routlegde

937 Smyth, W. \& Holmes, C., 2005. Using Carspecken's critical ethnography in nursing 938 research. Contemp Nurse, 19(1-2), 65-74.

939 Sparkes, A. C., \& Smith, B. (2009). Judging the quality of qualitative inquiry:

940 Criteriology and relativism in action. Psychology of sport and exercise, 10(5), 491-497. 
941 Spindler, L. (Ed.). (2014). Interpretive ethnography of education at home and abroad.

942 Psychology Press.

943 Spracklen, K., Timmins, S., \& Long, J. (2010). Ethnographies of the imagined, the

944 imaginary and the critically real: Blackness, whiteness, the north of England and rugby

945 league. Leisure Studies, 29(4), 397-414.

946 Spradley, J. P. (2016). The ethnographic interview. Waveland Press.

947 Surdyk A. (2006). Constructivist Character of the Technique of Role-Playing Games and

948 its Autonomizing Values in the Glottodidactic Process. Worlds in the Making.

949 Constructivism and Postmodern Knowledge ed. by E. Lorek-Jezińska, T. Siek-Piskozub,

950 and K. Więckowska, 173-185, Toruń.

951 Tarrant, C., Sutton, E., Angell, E., Aldridge, C. P., Boyal, A., \& Bion, J. (2017). The

952 'weekend effect'in acute medicine: a protocol for a team-based ethnography of weekend

953 care for medical patients in acute hospital settings. BMJ open, 7(4), e016755.

954 Van Maanen, J. (2011). Tales of the field: On writing ethnography. University of Chicago 955 Press.

956 Willis, P., 2009. Learning to labour: how working class kids get working class jobs.

957 Farnham: Ashgate

958 Wright, C., \& Schneider, A. (2010). Between art and anthropology: contemporary

959 ethnographic practice. Berg.

960 Yeo, R., \& Dopson, S. (2018). Getting lost to be found: the insider-outsider paradoxes in

961 relational ethnography. Qualitative Research in Organizations and Management: An

962 International Journal, 13(4), 333-355. 